\title{
Em busca das onças: as fotografias do jaguar sul-americano no relato de viagem de Theodore Roosevelt
}

\author{
In search of jaguars: photographs of the South American jaguar in \\ the report of Theodore Roosevelt's expedition
}

\section{Cecília Luttembarck Oliveira Lima Rattes ${ }^{i}$ \\ 'Integrante do Grupo de Estudos dos Animais - Coleção Brasiliana/ Universidade Federal de Minas Gerais. \\ Belo Horizonte - MG - Brasil orcid.org/0000-0001-5611-1859 ceciliarattes@yahoo.com.br}

Recebido em 14 jan. 2021. Aprovado em 19 maio 2021.
RATTES, Cecília Luttembarck Oliveira Lima. Em busca das onças: as fotografias do jaguar sul-americano no relato de viagem de Theodore Roosevelt. História, Ciências, Saúde - Manguinhos, Rio de Janeiro, v.28, supl., dez. 2021, p.221-234.

Resumo

Theodore Roosevelt viajou ao noroeste brasileiro em 1913 e 1914. Um dos seus objetivos era o de recolher informações sobre a fauna amazônica, especialmente a onça-pintada. Aliando fotografia e caça esportiva, Roosevelt desejava criar um repertório visual desse animal, mesclando-o à memória de suas conquistas. Entretanto, o terreno inóspito da floresta, o caráter furtivo e a rapidez dos movimentos das onças, assim como as limitações técnicas da fotografia, desafiaram suas pretensões. Examinaremos fotografias de animais produzidas por Roosevelt durante a viagem, assim como os retratos do Señor Lopez, famosa onça do Zoológico do Bronx, cujo registro, incorporado à narrativa da expedição, tornou-se relevante na memória da conquista, numa curiosa "representação do ausente".

Palavras-chave: fotografia; expedição científica; animais; onça-pintada; caça esportiva.

\begin{abstract}
Theodore Roosevelt traveled to northwestern Brazil in 1913-1914. One of his objectives was to collect information on Amazonian fauna, particularly the jaguar. Combining photography with hunting for sport, Roosevelt wanted to create a visual repertoire of this animal and add it into the record of his conquests. But the inhospitable forest, the furtive and quick jaguars, and the technical limits of photography challenged these aspirations. We will examine photographs of animals taken by Roosevelt during this trip, along with portraits of Señor Lopez, a famous jaguar at the Bronx Zoo, whose record, incorporated into the narrative of the expedition, became relevant in the memoirs of the conquest, as a curious "representation of the absent."
\end{abstract}

Keywords: photography; scientific expedition; animals; jaguar; sport hunting. 
$\mathrm{V}$ isualmente, o Brasil, em especial a região do noroeste brasileiro, ainda era um enigma para o público estadunidense. Porém, Theodore Roosevelt prometia "revelar" os segredos da vida e dos animais que a selva "escondia". Durante os anos de 1913 e 1914, Roosevelt empreendeu uma viagem ao Brasil, percorrendo territórios pouco explorados pelo homem branco. O ex-presidente dos EUA e o então coronel brasileiro Cândido Mariano da Silva Rondon, contando com o apoio financeiro do American Museum of Natural History, de Nova York, dividiram o comando de uma expedição, cujos objetivos eram caçar espécimes da fauna, registrar a flora da região, mapear o rio "desconhecido" e, se possível, fazer contato com os índios. A viagem teve grande repercussão, e o diário de Roosevelt (1914b), publicado primeiramente em forma de artigos na Scribner's Magazine, foi posteriormente transformado no livro Through the Brazilian wilderness (1914b). Seu relato era ricamente ilustrado e enfatizava as paisagens e os animais considerados exóticos e selvagens.

A edição de abril de 1914 da Scribner's Magazine anunciava que a narrativa seria "vívida e pitoresca", permeada por aventuras, desafios e histórias de caça ao jaguar, "o rei da América do Sul". Roosevelt demonstrou especial interesse pelo jaguar sul-americano, também conhecido como onça-pintada. A esta dedicou o capítulo "A jaguar-hunt on the Taguary", no qual a comparou, em força e brutalidade, aos leões e tigres, animais tidos como ferozes e "nobres para a caça" (Roosevelt, 1914b, p.79). Existia, nos centros urbanos, uma crescente demanda por informações e imagens dos grandes felinos. As representações de tigres e leões foram amplamente vinculadas, no imaginário da época, à ferocidade oriental e à violência desmedida, agudizando a associação entre a caça e o controle animal ao domínio da África e da Ásia (Mackenzie, 1988; Wonders, 2005; Haraway, 1993). Em sentido semelhante, utilizando-se de mecanismos discursivos e visuais pertencentes à cultura colonialista, Roosevelt apresentou o Brasil como uma região desocupada e perigosa, e a onça-pintada como uma ameaça, mas também como um troféu de caça altamente estimado. Nesse sentido, a fotografia deveria registrar a história natural e, principalmente, a memória da "conquista", da vitória sobre um ambiente hostil. Neste artigo privilegiaremos as representações da onçapintada apresentadas no relato de Roosevelt, evidenciando como essas imagens reforçaram a visão de um Brasil selvagem, atrasado e exótico.

As percepções do noroeste brasileiro, sobretudo da Amazônia, estavam imersas numa série de mitos históricos e preconceitos culturais relacionados à América Latina tropical. De acordo com Katherine Manthorne (1989), de todos os mitos que povoavam a região, o que mais se fortaleceu no imaginário do viajante estadunidense teria sido o da superabundância e da resistência da natureza tropical. Existia um verdadeiro fascínio por regiões percebidas como "fronteiras abertas", ou como áreas ainda desconhecidas pelo homem branco. Com matas virgens, extensos cerrados, montanhas e corredeiras, a região brasileira representava o tipo de "fronteira ilimitada", "ignota" e de aventura física radical. Poucos lugares na Terra, acreditava-se na época, poderiam oferecer experiências tão ricas, com uma fauna considerada "perigosa" e "primitiva".

Ao longo de sua vida, Theodore Roosevelt tornou-se um dos principais representantes de uma cultura centrada nos valores da masculinidade e na necessidade da experiência de viagem, do contato com os desafios da natureza, como forma de desenvolver a força e o autocontrole. Para ele, tais experiências seriam as responsáveis pelos fortalecimentos 
físico e espiritual do homem, assim como pelo surgimento de um senso de individualismo, do amor pela liberdade e da independência intelectual, características que supostamente teriam moldado a excepcionalidade do povo estadunidense. Assim, além de ter sido o $26^{\circ}$ presidente dos EUA (1901-1909), Roosevelt foi considerado por seus contemporâneos como naturalista, caçador, explorador, escritor e soldado militar; e teve a sua imagem associada ao homem forte e combativo. Fosse nos assuntos domésticos ou em suas relações internacionais, Roosevelt aparecia vinculado à representação do "grande conquistador" (Brinkley, 2009; Wilson, 2009). A viagem ao Brasil seria o coroamento de uma vida de desafios e vitórias (Orning, 1998; Millard, 2007).

Porém, assegurava o ex-presidente, "a viagem não foi planejada como uma simples caçada, e sim na forma de uma expedição científica" (Roosevelt, 1914b, p.26). Para ele, a expedição não se reduzia a fins recreativos ou de autopromoção, e, portanto, não deveria ser entendida como mera atividade de prazer. Roosevelt defendia que o esporte de caça aplicado adequadamente era o melhor aliado no desenvolvimento das pesquisas científicas, ajudando a fornecer e aumentar conhecimentos sobre determinada região. Em seu pensamento, os bons caçadores congregavam as habilidades necessárias para a tarefa científica, uma vez que seriam excelentes observadores, experientes no trabalho de campo e familiarizados com a história natural (Roosevelt, 1905; Wilson, 2009). O museu norte-americano desejava obter coleções zoológicas de espécies que habitavam a região noroeste do Brasil. O estudo de tal material poderia garantir grandes avanços nas pesquisas da fauna sul-americana, que, no momento, ainda eram incipientes.

No caso da onça-pintada, dizia Roosevelt, pouco havia se produzido sobre a sua biologia, e as escassas informações reunidas eram balizadas em "lendas infantis", sem qualquer cientificidade ou rigor crítico. Roosevelt observou que, de uma maneira geral, o jaguar (encontrado também, embora em menor número, no oeste norte-americano e na América Central) apresentava uma personalidade inofensiva e "covarde", uma vez que nunca atacava os seres humanos e raramente se defendia de maneira eficiente quando acossado. Porém, em alguns lugares da América do Sul, esses animais se tornariam agressivos e perigosos, verdadeira ameaça aos homens e à vida civilizada (Roosevelt, 1914b, p.28-32). Em suas palavras, nos confins do hemisfério sul, "o jaguar é há muito conhecido como um inimigo perigoso ..., sabendo-se também, que de vez em quando, se torna antropófago" (p.31). ${ }^{1} \mathrm{Em}$ sua lógica, o grau de agressividade estabelecia-se pelo ambiente em que o animal vivia: quanto mais perto da "civilização", mais dócil era o bicho, e, em contrapartida, quanto mais "selvagem" a região, mais perigosa sua população. No período, a dicotomia entre animais domésticos e animais selvagens era frequentemente comparada à que existia entre as "sociedades humanas civilizadas" e as "selvagens", criando-se a noção de que, em países cujos habitantes eram bárbaros, os animais tendiam a ser mais cruéis e ferozes (Haraway, 1993; Ritvo, 1987; Maxwel, 2000).

Roosevelt pertencia a uma tradição europeia vinculada ao pensamento judaico-cristão, que via a natureza como ameaça que deveria ser domada. A prática de "comer carne humana" simbolizava a rebelião do mundo animal contra uma ordem supostamente estabelecida por Deus, cuja violação deveria ser punida com a morte (Ritvo, 1987; Thomas, 2010; Ryan, 1997). Ao indicar que o animal era antropófago, tornava-se justificável (e necessária) a sua 
caça, assegurando a manutenção da ordem divina e a restauração dos princípios civilizados. Assim, ao matar os jaguares, Roosevelt colocava sua caça como um ato altruísta, já que as onças brasileiras eram supostamente famosas pelos ataques às comunidades ribeirinhas e aos rebanhos domésticos. Não por acaso, a primeira imagem de onça-pintada apresentada no diário foi o retrato do autor com o animal abatido (Figura 1). Na fotografia, realizada por seu filho Kermit, Theodore Roosevelt vestia a convencional roupa europeia dos safaris africanos e portava uma espingarda. O cenário ao fundo resgatava a ideia de um ambiente remoto, de mata fechada. Sua postura era confiante diante da câmera, e, agachado, ele apresentava ao público a carcaça do animal morto, vencido. Roosevelt encarnava o estereótipo da figura heroica e colonizadora e exibia o bicho abatido como troféu de sua conquista. James Ryan (1997) observou que os retratos de "homens brancos" próximos a animais mortos eram comuns, e até mesmo um clichê, nas fotografias coloniais do século XIX. Elas passaram a configurar a maneira mais tradicional de exibição de poder, da superioridade humana em relação à natureza.

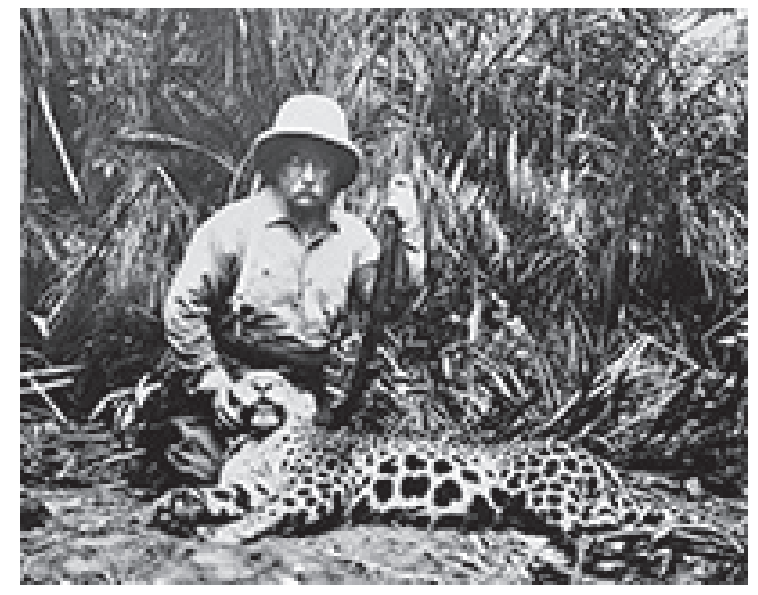

Figura 1: Roosevelt e o primeiro jaguar; fotografia de Kermit Roosevelt (Roosevelt, 1914b, p.80-81)

As fotografias de caça apresentavam claras conotações simbólicas sobre as relações humanas com a natureza e, sobretudo, com as relações estabelecidas entre "raças", povos e nações. Estudos como os de Donna Haraway (1993), Harriet Ritvo (1987) e William Storey (1991) demonstraram que a forma como os seres humanos se relacionavam com os animais e o ambiente poderia ser usada como elemento-chave na leitura sobre como os homens concebiam a si mesmos e o "outro". De modo geral, na cultura colonialista, os animais foram imaginados como arquetípicos do "outro", representados como inimigos ou fiéis aliados, desempenhando um papel importante na construção simbólica da natureza e da identidade humana. Assim, conforme as pessoas dominavam os ambientes em que os animais viviam, enquanto cães e cavalos se multiplicavam, as populações de tigres, leões e onças-pintadas eram eliminadas. As fotografias do caçador com a presa ampliavam a compreensão do simbolismo animal e da dominação humana sobre o ambiente, bem como revelavam a violência que permeava a interação entre as diferentes culturas. 
O retrato de Roosevelt com a onça-pintada evidencia um espaço semiótico no qual o animal morto, ao ser posteriormente colocado em exposição pública, atingia um significado político e cultural. Nos EUA, com a justificativa nacionalista do Destino Manifesto, surgiria ainda mais forte a ideia dos valores superiores dos norte-americanos e de seu dever - e predestinação - de dominar qualquer território que fosse classificado como bárbaro e inculto (Turner, 1996; Nash, 1982; Junqueira, 2000). Por mais que não existisse um plano de colonização, existia a construção de um aparato discursivo e de um sistema de conhecimento que implicava, em determinadas esferas, um posicionamento de dominação e superioridade de uma nação sobre a outra. Sob o discurso da ciência e do progresso, o noroeste brasileiro seria construído, na narrativa de Roosevelt, como um lugar ainda abandonado, marginal e habitado por animais selvagens, porém, pronto para receber a "ajuda" da "raça" branca, forte e empreendedora, com conhecimentos e disposição física para dominar o território.

Nas publicações, junto à imagem, vinha a descrição do contexto e, principalmente, das características do animal. Na fotografia acima (Figura 1), Roosevelt tentou equiparar o exemplar abatido, em tamanho e ferocidade, a outros grandes felinos. O critério das dimensões do bicho introduzia a equação entre o poder físico da presa e as proezas do atleta que a venceu. Roosevelt sabia que o tamanho da onça consagrava a sua habilidade de caçador, aumentando a estima do público pelo feito. O animal, posicionado no primeiro plano, adquiria uma proporção maior, além de receber destaque na imagem. $\mathrm{Na}$ tentativa de formular um critério inteligível para os leitores, o ex-presidente lançou mão da estratégia da comparação, como forma de melhor dimensioná-lo: "O animal tinha mais peso e volume do que um cougar adulto macho ou uma pantera ou um leopardo africano", e "era forte e grande" como um tigre e um leão (Roosevelt, 1914b, p.79). Esse cotejo visava hierarquizar o valor da onça como troféu, destacando o potencial perigo que o felino representava.

Tamanho e ferocidade eram qualidades caras, porém, outros elementos também eram determinantes na designação do valor do animal. Os exemplares machos eram universalmente preferidos como troféus da conquista (Ritvo, 1987; Haraway, 1993). Roosevelt desejava caçar mais espécimes masculinos, chegando a reclamar por diversas vezes. O então comandante da Marinha brasileira, Heitor Pereira da Cunha (1922, p.37), que encontrou a comitiva de Roosevelt na Fazenda Palmares, relatou em seu livro um desses episódios: "Roosevelt, que até então havia limitado os seus conhecimentos em português à palavra 'obrigado' e à frase 'mais café', ampliou a aplicação do nosso idioma reclamando por duas vezes 'mais onça'”. Na expedição, foi seu filho Kermit quem atirou a derradeira bala na onça macho, mas isso não impediu o ex-presidente de despender algumas linhas para descrever o bicho: era um "belo troféu", com "o dobro de peso de qualquer leopardo africano" e "possuía grandes ossos, arcabouço reforçado e uma forte compleição muscular, como se fosse um pequeno leão" (Roosevelt, 1914b, p.81-82).

A onça macho, embora altamente valorizada no relato de Roosevelt, foi encontrada em basicamente duas imagens: em uma fotografia com Rondon (Figura 2), cujo padrão estético se assemelha ao do retrato de Roosevelt com a onça fêmea; e na fotografia do animal já preparado para ser futuramente taxidermizado (Figura 3). Ambas as imagens foram também 
produzidas por Kermit Roosevelt, autor do disparo, que, curiosamente, preferiu assumir a função de fotógrafo do que a de caçador orgulhoso. É interessante notar que a expedição contava com dois fotógrafos oficiais: o estadunidense Anthony Fiala e o brasileiro Thomaz Reis (Roosevelt, 1914b; Rondon, 1916). Entretanto, outros membros da comitiva também produziram imagens, entre eles, o mastozoólogo Leo Miller e o ornitólogo George Cherrie. Isso sugere que foi uma escolha de Kermit Roosevelt não aparecer na fotografia, e não a falta de mão de obra para a tarefa.

Foi dado a Rondon o papel de posar ao lado da onça macho. No retrato, o animal também foi disposto no primeiro plano, de forma a destacar as suas dimensões. Rondon, posicionado na lateral direita, segurava o felino pela mandíbula e exibia suas presas. A apresentação dos dentes afiados do animal reforçaria a ideia de sua ferocidade e, por conseguinte, de seu apetite por carne. A fotografia chegou a ser publicada na Scribner's Magazine, na edição de maio 1914, mas, embora, estética e narrativamente, fosse mais atraente do que o retrato de Roosevelt com a onça fêmea, foi excluída do livro. Ainda que Rondon dividisse o comando da expedição e possuísse certo destaque na história, o fato de a família Roosevelt não estar presente na imagem, sem dúvida, foi crucial na decisão de suprimir da edição do livro a representação do principal troféu da viagem.

Já a fotografia da onça macho preparada para a taxidermia, mesmo contando com a presença do ex-presidente, não chegou a ser divulgada nos meios de comunicação impressos da época. No registro, Roosevelt e Rondon, cada um segurando uma pata do animal, e outro integrante (não identificado), com a cabeça, apresentavam a carcaça do bicho. $\mathrm{O}$ ambiente indicava que a equipe já se encontrava em um acampamento, com a presença de equestres em um pasto cercado ao fundo. O animal desmontado, sem as suas dimensões reais e aspecto vivo, não mais suscitava o temor de antes, o que pode explicar a circulação restrita que a imagem alcançou. Possivelmente, ela foi utilizada como uma amostra dos objetivos científicos da viagem, reforçando o apelo conservacionista da missão, ao apresentar o animal abatido não como um simples troféu, mas como um exemplar a ser acrescentado à coleção de história natural.

Ainda que existisse uma justificativa científica nessas produções visuais, esse tipo de fotografia dificilmente apresentava informações "claras", "objetivas" e "relevantes" para o desenvolvimento do conhecimento da fauna. Sua estrutura compositiva e a escolha de um grupo restrito de animais não poderiam ser explicadas em termos de projeção educativa ou técnica, mas apenas como referências ao valor conflitivo presente no esporte de caça. Ao produzir a fusão entre "vencedor e vencido", elas funcionariam como um meio pelo qual o caçador poderia apropriar-se de algumas das qualidades associadas ao animal e/ou ao seu habitat. Assim, contribuiriam para a definição do esportista e do caçador-naturalista em termos de uma masculinidade intrínseca, e para o estabelecimento de uma forte conexão entre a caça e o discurso de controle e conquista. 


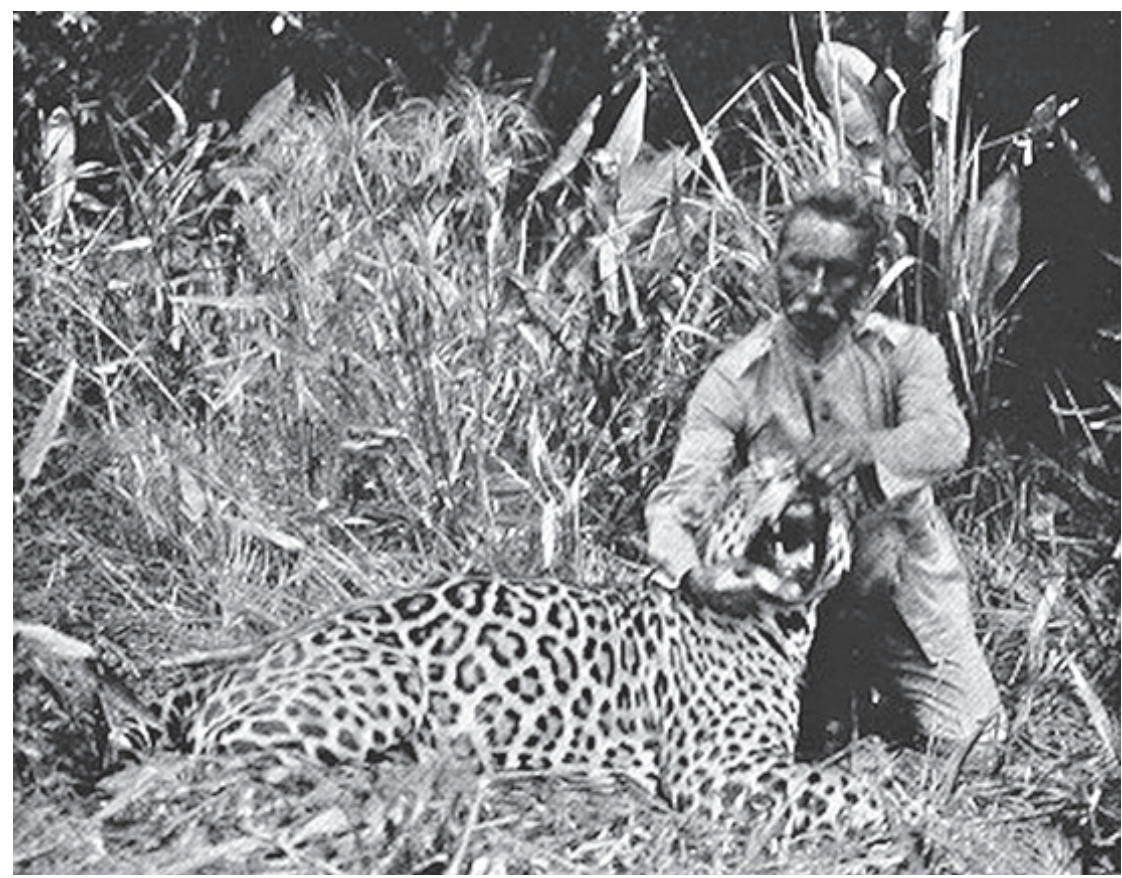

Figura 2: Rondon com o segundo jaguar; fotografia de Kermit Roosevelt (Roosevelt, 1914a, p.549)

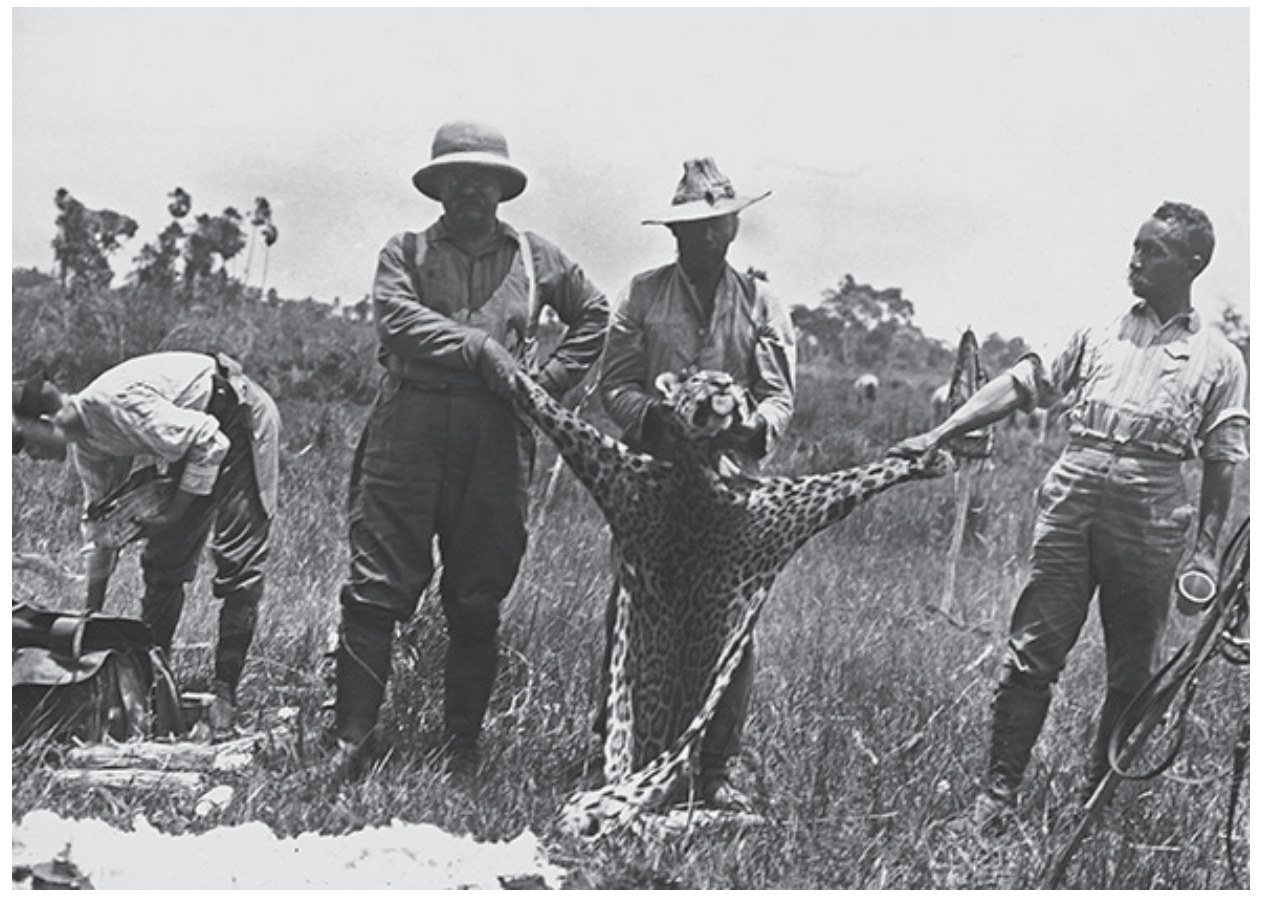

Figura 3: Theodore Roosevelt e Cândido Rondon segurando a pele de um jaguar durante a Expedição Científica Roosevelt-Rondon; fotografia de Kermit Roosevelt, 1913 (Biblioteca do Congresso, Washington, DC) 
De maneira geral, a viagem de Roosevelt ao Brasil pode ser dividida em três fases. A primeira foi destinada às palestras e obrigações oficiais nos centros urbanos, como Rio de Janeiro e São Paulo. A segunda envolveu um deslocamento por meio fluvial e por terra até a estação telegráfica de Tapirapuã. Contava com o apoio de um iate-canhoneira paraguaio, como transporte fluvial, e de diversas cidades e fazendas localizadas nos arredores, como a Fazenda Palmares, que serviriam de alojamento e postos de abastecimento. E a terceira fase, que correspondia à descida do rio da Dúvida, batizado posteriormente de rio Roosevelt. Esta última fase se mostrou a mais desafiadora, deixando o ex-presidente à beira da morte. $\mathrm{O}$ interior denso da floresta amazônica revelava-se como um mundo estranho e implacável, e os conhecimentos, antes aplicados com êxito nos safaris africanos ou nas investidas de caça no oeste norte-americano, pareciam insuficientes para aquela realidade (Orning, 1998; Millard, 2007). A tarefa de garantir as provisões e os espécimes zoológicos era árdua. $\mathrm{O}$ zoólogo George Cherrie (1914, p.48) concluiu: "Vê-se muito pouca vida animal ao longo da margem".

Assim, ao contrário do terreno enlameado e de mata fechada da Amazônia, as caçadas e, por conseguinte, os seus registros aconteceram na Fazenda Palmares, propriedade localizada na atual região do Mato Grosso e famosa por concentrar muitos animais silvestres (Millard, 2007; Rattes, 2015). A segunda fotografia da onça macho revelava esse ambiente, com a presença de referências à civilização, como a cerca que demarcava o pasto. Mas, apesar do relativo conforto de que gozava, Roosevelt salientou o ambiente desafiador e os sentimentos de entusiasmo da equipe, envolvendo o leitor em uma verdadeira trama de aventura: "O latido furioso da matilha, os gritos de encorajamento dos cavaleiros, os arredores da selva, o medo que a fera impõe - tudo isso combinado torna o momento angustiante e emocionante" (Roosevelt, 1914b, p.81).

O encontro entre o caçador e o felino era descrito como uma "luta esportiva", mesmo quando as iniciativas contra o animal eram bastante antidesportivas. De fato, o risco de vida nesse tipo de embate era mais imaginado do que real, já que eram raros os momentos em que o animal se tornava o "predador". O homem portava armas modernas, com precisão e velocidade. Não existia no período uma política que oferecesse proteção legal aos animais ou regra que tornasse a luta mais equilibrada. Porém, reconhecer a existência desse desequilíbrio poderia desqualificar a caça em toda a sua essência e glória. Era necessário que os caçadores abandonassem, em seus relatos, qualquer descrição de vulnerabilidade que os animais pudessem apresentar, atribuindo-lhes características como "perigosos", "ferozes" e "sanguinários", para então associá-los a um comportamento violento. Também era comum nos relatos a descrição das cenas de morte dos animais, em que se registravam suas feições e a coragem diante da morte: "Era uma bela imagem - a pelagem manchada do grande, ágil e formidável gato brilhava enquanto rosnava a desafiar a matilha. ... Com o tiro, o jaguar caiu ... e, embora vacilante nas patas, não pode dar senão poucos passos e deixou-se esvair" (Roosevelt, 1914b, p.78-79). A narrativa explicitava a agressividade do bicho, mas também comportava algum nível de admiração pelo felino, transformando a onça, de objeto, em personagem coadjuvante do relato. Afinal, quanto mais desafiador parecesse o animal, mais justificado seria o papel do caçador e, consequentemente, 
mais impressionante o troféu, entendido como símbolo da vitória humana sobre a força selvagem do animal.

Existia também a ideia de se fazer uma séria de imagens da onça viva, em seu habitat natural. Roosevelt era defensor do valor da fotografia na pesquisa científica e em viagens expedicionárias. Havia a crença na capacidade mimética e imparcial da imagem fotográfica, transformando o aparelho óptico em um importante instrumento de "captação do real". Além disso, o ex-presidente confiava que a fotografia poderia transformar, em grande medida, o próprio esporte de caça, ao substituir a "arma de fogo" pela "câmera". Ele defendia que o uso do aparelho fotográfico nos safáris e expedições científicas conseguiria reunir no seio de sua prática todas as qualidades do esporte de caça - entre elas, o desenvolvimento da masculinidade - e a conservação dos animais e do meio ambiente (Roosevelt, 1894; 1905). Para ele, a técnica fotográfica apresentaria desafios maiores que a simples caçada e produziria um troféu (a imagem fotográfica) sem, contudo, interferir a natureza, mesmo que, na prática, o resultado de suas experiências implicasse, invariavelmente, na morte do animal. Em viagens anteriores, como o safári à África, em 1909-1910, e as diversas incursões que empreendeu ao Oeste norte-americano, Roosevelt integrou a câmera fotográfica como parte de seus equipamentos. As imagens produzidas durante as campanhas seriam apresentadas como registros da história natural e utilizadas como informações para recriar o ambiente tropical nas revistas e, posteriormente, nos museus (Rattes, 2015).

Como Roosevelt havia repetidamente ponderado, pouco se produziu sobre a vida e o comportamento in loco desse felino e, portanto, a possibilidade de se criar, por meio da fotografia, uma galeria de dados acurados e ao alcance dos olhos era sedutora. O fotógrafo brasileiro Thomaz Reis, que integrava a equipe de Rondon nessa fase da expedição, havia apresentado a Roosevelt uma proposta de filmagem da caça à onça-pintada. Além de alimentar o interesse popular e enaltecer a sua imagem como explorador e herói, Roosevelt produziria conhecimentos científicos confiáveis e inéditos, segundo a concepção da época. Não se trataria mais de retratos posados, mas da "captura do real", de informações apenas reveladas pelo poder da máquina óptica. As filmagens ainda serviriam como suporte para expressar os sentimentos e as emoções da caçada, que ficavam restritos, até então, aos relatos escritos. Mas a ideia provou-se inviável e foi descartada, em razão das limitações técnicas, das dificuldades impostas pela mata fechada e pela total falta de controle sobre o comportamento do animal. Thomaz Reis, em 1916 e 1917, chegou a realizar filmagens da caçada à onça-pintada. Frustrado, concluiu, em seu relatório à Comissão Rondon, que os resultados foram insatisfatórios. Para o fotógrafo, a luz, a vegetação, a mudança constante de posição, a cor do animal, que se misturava com os tons de cinza da mata, e o próprio medo do felino, que, mesmo acuado, não atacava, tornavam a narrativa dos eventos confusa e monótona (Tacca, 2007; Reis, 1945).

Assim, Roosevelt e sua equipe não produziram outros registros das onças-pintadas brasileiras, limitando-se aos retratos dos dois animais mortos. Mas, então, como abastecer um público sedento por informações, que aguardava imagens do temido felino? Para solucionar o problema e suprir a demanda por fotografias de animais vivos (não apenas da onça-pintada), o ex-presidente decidiu utilizar as imagens produzidas por Elwin Sanborn, o fotógrafo contratado do Bronx Zoo, de Nova York. Não se sabe ao certo se as imagens 
publicadas, primeiramente na Scribner's Magazine, e posteriormente no diário de viagem, foram frutos de uma encomenda ou se já faziam parte do acervo fotográfico de Sanborn. Porém, não resta dúvida de que a opção pelo uso das imagens do fotógrafo profissional expunha a dificuldade da expedição em produzir fotografias "vivas" dos animais no Brasil, como foi o caso não apenas da onça-pintada, mas também da anta, do tamanduá e de outros animais.

O uso de equipamentos profissionais por Sanborn oferecia imagens com qualidade, alto grau de nitidez e em formatos maiores e variados, embora sem as sequências emocionantes, do tipo que Thomaz Reis ansiava realizar. Elas seguiam os requerimentos expressos pelos membros do zoológico, que desejavam imagens estáticas e objetivas, de forma a mostrar a "exata" fisionomia do animal em sua expressão natural. As fotografias deveriam ser uma espécie de broadside, nas quais as informações sobre os animais apareceriam de forma clara, além de apresentadas em uma composição aprazível ao olhar (Bridges, 1974). Dessa forma, o artista, o taxidermista ou mesmo um curioso leigo da história natural poderiam dispor de todos os detalhes físicos de uma maneira "prática", "neutra" e "científica".

Possivelmente, o "jaguar sul-americano" representado por Sanborn (Figura 4) era o famoso felino do zoológico conhecido como Señor Lopez. O animal havia sido adquirido em 1902, como presente oferecido por William Butler, o vice-cônsul do Paraguai na Filadélfia. Durante a sua viagem à capital paraguaia, Butler conseguiu comprar de caçadores locais um "tigre de seis meses de idade, muito bonito e grande" (Butler citado em Bridges, 1974, p.134). Ele era considerado um animal forte, feroz e agressivo, "mesmo para a sua própria espécie". Essa fama ganhou notoriedade após o incidente de 1905, quando os organizadores do zoológico resolveram trazer uma fêmea para lhe fazer companhia. No momento em que a colocaram na jaula, Señor Lopez a atacou instantaneamente, provocando a sua morte. $\mathrm{O}$ jornal New York Times, do dia 17 de dezembro de 1905, ao recontar a história, apresentou um argumento interessante: por mais que aquela onça fosse um animal criado dentro dos muros do zoológico, suas inclinações selvagens não foram suprimidas por uma vida em cativeiro. Ou seja, embora não mais vivesse na selva, ele ainda possuía uma "personalidade assassina" e portava-se como legítimo representante de sua espécie. A ideia do determinismo geográfico era resgatada como forma de explicar seu comportamento, em sentido oposto aos ideais morais da domesticação e, por conseguinte, da civilização.

Señor Lopez foi o primeiro habitante da nova ala do zoológico, construída, em 1903, para abrigar os grandes felinos e conhecida como Lion House. O edifício possuía duas salas, localizadas na parte norte, reservadas para o uso exclusivo de artistas naturalistas. Desde 1896, já havia o manifesto interesse da sociedade de produzir, dentro da instituição, representações científicas e artísticas dos animais. Um dos estúdios possuía uma espécie de túnel que ligava a jaula ao quarto e possibilitava a visualização do animal de um ponto mais próximo e seguro. Sanborn facilmente tinha acesso àquela infraestrutura. Seu contato contínuo com o animal possibilitava captar, repetidamente, imagens mais nítidas e mais detalhadas de sua fisionomia, qualidades que dificilmente as fotografias da expedição ao Brasil alcançariam. 


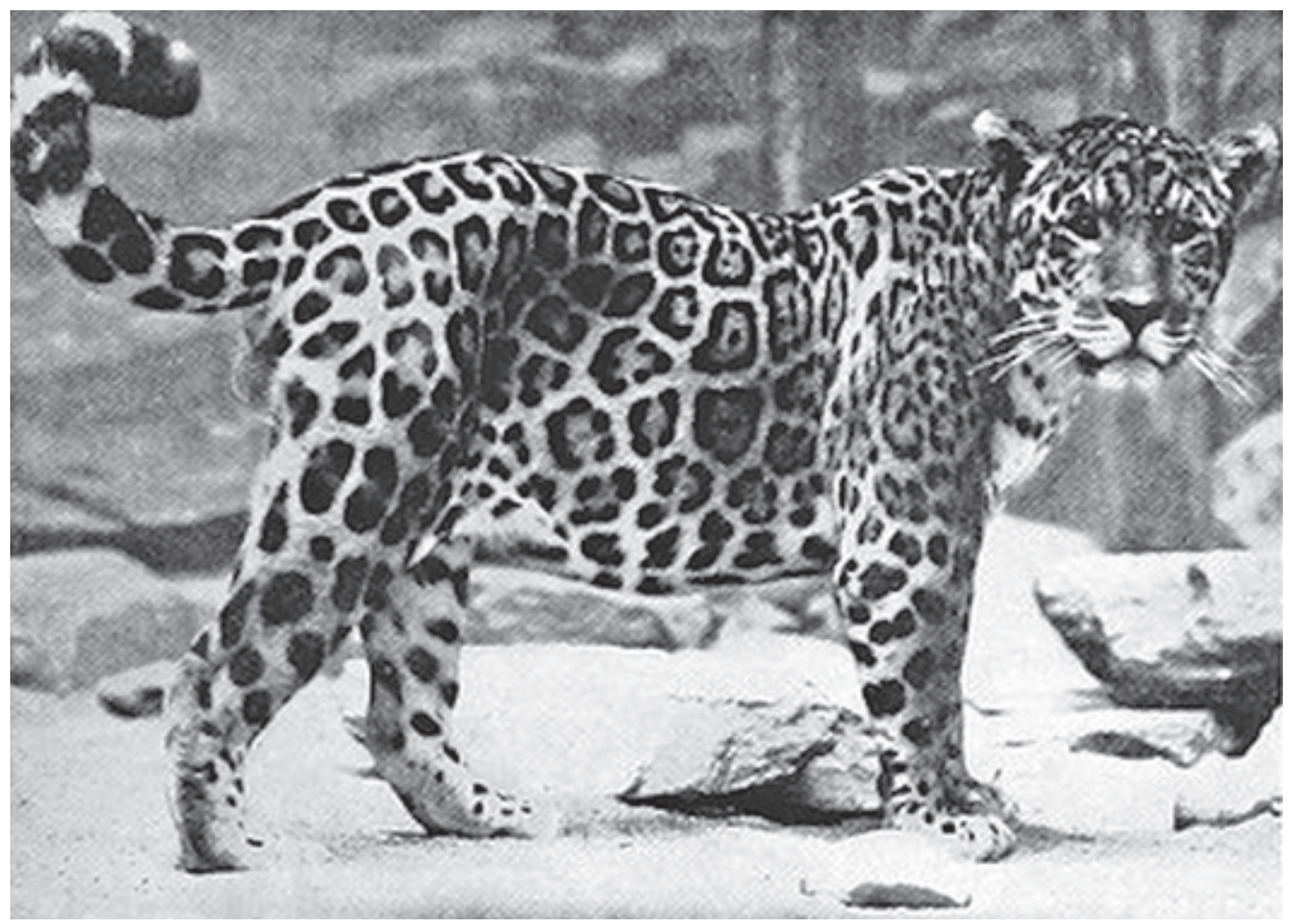

Figura 4: A South American jaguar; fotografia de Elwin Sanborn (Roosevelt, 1914b, p.84)

Em 1906, o zoológico do Bronx produziu uma série de cartões-postais dos animais presentes na instituição. Entre eles, a fotografia colorida do Señor Lopez (Figura 5), retratando o felino dentro de sua jaula. A imagem publicada na Scribner's Magazine e no livro de Roosevelt apresentava similaridades com esse cartão-postal, tais como posição do animal, ângulo e enquadramento da composição. Essas características poderiam fortalecer a hipótese de que o ex-presidente apenas adquiriu imagens previamente produzidas dos animais para compor a sua narrativa. Possivelmente, tanto a figura publicada nos relatos de Roosevelt quanto o cartão-postal comercializado no zoológico faziam parte de uma série de fotografias produzidas por Sanborn com aquela temática. De qualquer forma, por mais que fotografias como essas não apresentassem o ambiente natural dos animais, elas ajudavam a dar forma à narrativa de aventura de Roosevelt. De acordo com as descrições da época, era possível que Señor Lopez fosse, aliás, uma onça de tamanho superior ao dos dois animais abatidos no Brasil. No livro Viagens e caçadas em Mato Grosso, Heitor Pereira da Cunha (1922) assim descreveu a onça fêmea abatida por Roosevelt: "Era uma onçapintada, fêmea, medrosa e de fracas dimensões; pena é que o nosso ilustre hóspede não tivesse assistido ao combate de um 'macharrão' malcriado, acuado no mato sujo" (p.34). Señor Lopez tornaria a visualização mental da cena ainda mais emocionante. 


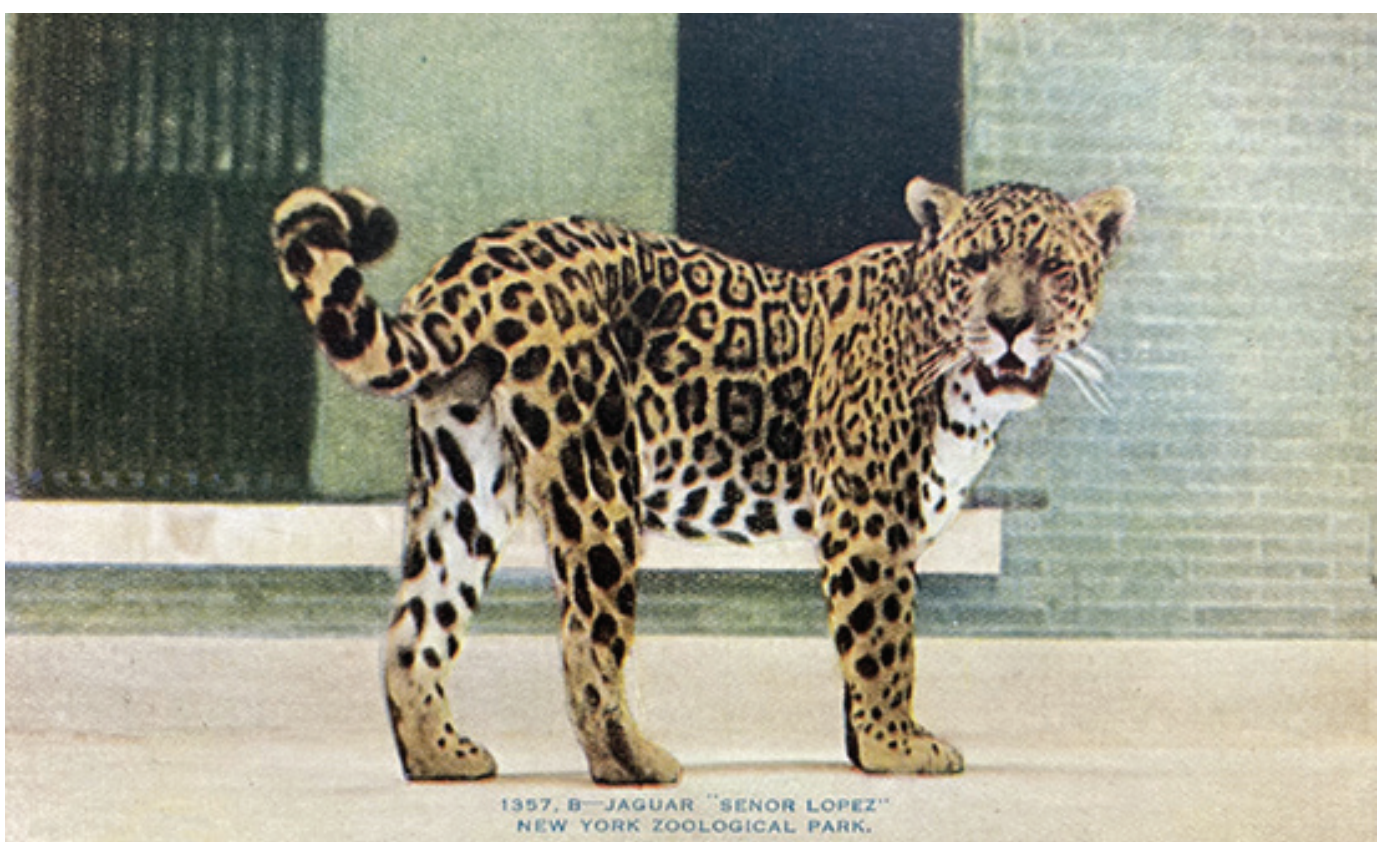

Figura 5: Jaguar Señor Lopez, New York Zoological Park, cartão-postal; fotografia de Elwin Sanborn, c. 1906 (coleção particular).

Mesmo sem os desafios técnicos e físicos impostos pela floresta, a imagem do Señor Lopez passou a subsidiar um discurso de controle e conquista, quando reproduzida nos diários de viagem ou exibida junto às outras representações da comitiva. O historiador e filósofo polonês Krzysztof Pomian (1984), em artigo publicado na Enciclopédia Einaudi, explicou sobre a capacidade dos objetos de exceder a sua materialidade, contribuindo com os modos de sentir e agir expressos na sociedade. Segundo o estudioso, não importa o objeto em si, mas o valor que reside em sua força simbólica, em seu caráter representativo do invisível ou de uma memória do ausente. Ao ser incorporada à coleção visual da Expedição RooseveltRondon, a fotografia do Señor Lopez adquiriu uma conotação diferente daquela que lhe foi inicialmente atribuída, tornando-se um "semióforo", ou seja, a sua importância não mais correspondia ao valor de uso, mas ao significado que lhe era imputado. Nesse caso, a fotografia produzida por Sanborn acumulou valores e sentidos referentes à sua produção histórica e foi utilizada (interpretada e apropriada) para outras finalidades ao longo de sua trajetória documental.

Embora não fosse resultado do material feito no Brasil, ela foi adicionada por Roosevelt à série fotográfica da fauna brasileira e serviu como ilustração das temidas onças-pintadas. Sua divulgação em periódicos, livros e, possivelmente, palestras sugere que tenha alcançado um alto grau de visibilidade. Estima-se que, na ocasião, a tiragem da Scribner's Magazine tenha chegado aos 215 mil exemplares (Gaipa, s.d.). Assim, ao tornar-se pública, a fotografia do Señor Lopez, inserida dentro do contexto da expedição, assumiu a tarefa de instruir, informar e entreter, evocando valores, lembranças e experiências vividas pelo ex-presidente. Ela se transformou em representação do ausente e atuou de maneira 
efetiva na construção da narrativa da viagem, remodelando a memória da conquista sobre o território brasileiro.

Por meio de suas fotografias e do relato escrito, Roosevelt produziu um mundo colonial amazônico. Ele reconstruiu e se apropriou de tudo aquilo que era de seu interesse ou da sua audiência. De acordo com Boris Kossoy (2002, p.83), quando se tratava de fotografia do Brasil, esperava-se encontrar, nas revistas estrangeiras e nos grandes espetáculos científicos internacionais, imagens da vegetação e de sua fauna exuberante e "canibal", que faziam parte do imaginário imperialista eurocêntrico da época. Como foi visto, havia uma preocupação editorial latente, e, pensando em seu leitor ideal, o ex-presidente selecionou o conteúdo a ser publicado, ou seja, cortou passagens, inseriu dados, trocou palavras, sequenciou os capítulos, e, obviamente, fez um trabalho de memória que, na sua percepção, recriaria "fielmente" a viagem ao Brasil. Suas imagens da onça-pintada eram construídas e inseridas no relato sinalizando uma lógica de organização e pensamento, de ordenação de espaços sociais e de mediação dos tempos culturais, tornando-se representações do mundo que refletiam os códigos culturais de seu produtor. A natureza - delimitada pela narrativa escrita e visual - era idealizada e apresentada como sem história; mas também como propícia para aventuras e para subsidiar avanços científicos. Roosevelt olhava para a região com os "olhos do império", e, ao retratá-la como "primitiva", "desocupada" e "selvagem", validava sua presença e autorizava futuras investidas estrangeiras sobre o território brasileiro.

\section{AGRADECIMENTOS}

Agradeço ao Centro de Estudos dos Animais, em especial às colegas Regina Horta e Natascha Ostos, pelo diálogo ao longo do processo de elaboração deste artigo. Agradeço também aos pareceristas anônimos por suas contribuições.

\section{NOTA}

${ }^{1}$ Nessa e nas demais citações de textos em inglês, a tradução é livre.

\section{REFERÊNCIAS}

BRIDGES, William. Gathering of animals: an unconventional history of the New York Zoological Society. New York: Harper \& Row, 1974.

BRINKLEY, Douglas. The wilderness warrior: Theodore Roosevelt and the crusade for America. New York: HarperCollins, 2009.

CHERRIE, George K. Cherrie's diary of the Theodore Roosevelt Expedition to explore the River of Doubt in Brazil, October 1913 to May 1914 (American Museum of Natural History, New York). 1914.

CUNHA, Heitor Pereira da. Viagens e caçadas em Mato-Grosso: três semanas em companhia de Th. Roosevelt. Rio de Janeiro: Oficinas Gráficas da Livraria Francisco Alves, 1922.
GAIPA, Mark. Scribner's Magazine: an introduction to the MJP Edition, 1910-1922. Modernist Journals Project, s.d. Disponível em: https://modjourn.org/scribners-magazinean-introduction-to-the-mjp-edition-19101922/\#Appendix_1. Acesso em: 10 set. 2015.

HARAWAY, Donna. Teddy Bear patriarchy: taxidermy in the Garden of Eden, New York City, 1908-1936. In: Kaplan, Amy; Pease, Donald (ed.). Cultures of United States imperialism. Durham; London: Duke University Press, 1993. p.237-229.

JUNQUEIRA, Mary Anne. Ao sul do rio Grande - imaginando a América Latina em seleções: oeste, wilderness e fronteira (1942-1970). Bragança Paulista: Edusf, 2000. 
KOSSOY, Boris. Realidades e ficções na trama fotográfica. São Paulo: Ateliê Editorial, 2002.

MACKENZIE, John M. The empire of nature: hunting, conservation and British imperialism. Manchester: Manchester University Press, 1988.

MANTHORNE, Katherine. Tropical Renaissance: North American artists exploring Latin America, 1839-1879. Washington; London: Smithsonian Institution Press, 1989.

MAXWELL, Anne. Colonial photography and exhibitions: representations of the "native" and the making of European identities. London; New York: Leicester University Press, 2000.

MILLARD, Candice. O rio da Dúvida: a sombria viagem de Theodore Roosevelt e Rondon pela Amazônia. São Paulo: Companhia das Letras, 2007.

NASH, Roderick. Wilderness and the American mind. New Haven; London: Yale University Press, 1982.

ORNING, Joseph. My last chance to be a boy: Theodore Roosevelt's South American expedition of 1913-1914. Baton Rouge: Louisiana State University Press, 1998.

POMIAN, Krzysztof. Coleções. In: Le Goff, Jacques (ed.). Enciclopédia Einaudi, 1: memória e história. Lisboa: Imprensa Nacional-Casa da Moeda, 1984. p.51-86.

RATTES, Cecília Luttembarck O. Lima. A viagem de Theodore Roosevelt pelo noroeste brasileiro: caça, ciência e representações da floresta tropical. Tese (Doutorado em História) - Universidade Federal de Minas Gerais, Belo Horizonte, 2015.

REIS, Luiz Thomaz. Relatórios dos Serviços Fotográficos e Cinematográficos e Serviços Antropométricos. In: Vasconcelos, Capitão Vicente de Paulo Teixeira da Fonseca. Expedição ao rio Ronuro. Rio de Janeiro: Imprensa Nacional, 1945. p.99-123.

RITVO, Harriet. Animal Estate. Cambrigde, MA: Harvard University Press, 1987.
RONDON, Cândido Mariano da Silva.

Conferências realizadas nos dias 5, 7 e 9 de outubro de 1915 pelo Sr. Coronel Cândido Mariano da Silva Rondon no Theatro Phenix do Rio de Janeiro. Rio de Janeiro: CLTEMTA, 1916.

ROOSEVELT, Theodore. A hunter-naturalist in the Brazilian wilderness. Scribner's Magazine, v.55, n.5, p.539-558, 1914a.

ROOSEVELT, Theodore. Through the Brazilian wilderness. New York: Charles Scribner's Sons, 1914b.

ROOSEVELT, Theodore. Outdoor pastimes of the American hunter. New York: Charles Scribner's Sons, 1905.

ROOSEVELT, Theodore. Introduction. In: Wallihan, Allen; Wallihan, Mary. Hoofs, claws and antlers of the Rocky Mountain. Denver: Frank S. Thayer Publisher, 1894.

RYAN, James. Picturing Empire: photography and the visualization of British Empire. Chicago: The University of Chicago Press, 1997.

STOREY, William K. Big cats and imperialism: lion and tiger hunting in Kenya and Northern India, 1898-1930. Journal of World History, v.2, n.2, p.135-173, 1991.

TACCA, Fernando de. Caça de onças: um relato etnográfico de um filme perdido de Luiz Thomaz Reis. Somalu, v.7, n. especial, p.37-46, 2007.

THOMAS, Keith. O homem e o mundo natural: mudanças de atitudes em relação às plantas e aos animais (1500-1800). São Paulo: Companhia das Letras, 2010.

TURNER, Frederick Jackson. The frontier in American history. New York: Dover Publications, 1996.

WILSON, Robert L. Theodore Roosevelt: hunterconservationist. Missoula: Boone and Crockett Club, 2009.

WONDERS, Karen. Hunting narratives of the Age of Empire: a gender reading of their iconography. Environment and History, v.11, n.3, p.269-291, 2005.

\section{$\rightarrow \rightarrow \rightarrow<<<$}

